\title{
Cultivation of Autonomy and Independence
}

\author{
Yuan Wang \\ School of Foreign Language \\ Kunming University \\ Kunming, Yunnan, 650214
}

\begin{abstract}
This thesis probes into the validity and significance of the application of critical thinking to the cultivation of autonomy and independence in college English reading. During the college reading teaching, with the device of positive psychology theories, the traditionally examination-oriented teaching mode is adjusted and reformed effectively to the direction of developing and promoting students' thinking quality. On the platform of critical reading, students are supposed to learn actively and consciously discarding these habits that restrain their minds and autonomy. Effective strategies of critical thinking training are put forward in this paper, which finally lead to student autonomy in the thinking and learning process. These strategies can be summarized as: Socratic questioning training; Objectives analyzing; Setting and adjusting of schedule; Testing of the effectiveness.
\end{abstract}

\section{Keywords—critical thinking; autonomy; English reading}

\section{INTRODUCTION}

As major access to information, reading is the magnificent task for English learning. English learners as a second language always keep pushing to improve the ability to read original works and materials smoothly and freely. Therefore, English-reading teaching plays a vital role in college English course. The mainstream theories on English learning attach a great deal of importance on the decisive role of the learners, which can be summed up as autonomy.

Since the 1970s, relative foreign researchers have focused on learners' autonomy in second language learning, whose study center on the definition of autonomy in foreign language learning. (Holec 1981; Allwright 1990; little 1991; Littlewood 1999). Meanwhile, their studies also cover the basic theoretical research of autonomy, practical strategies, courses arrangement and practical results analysis. (Wenden 1987; Dickinson 1992; Cotterall and Crabbe1999; Cotterall 2000). While the domestic researchers have mainly introduced and analyzed these foreign research results since the 1980s, which confined their scope to the discussions including needs of autonomy developing and related teaching programs designing. ( Zhou Xingqi 1998; Zhen Ming2000; Hua Weifen 2001,2002; Peng Jinding 2002; Wei Yuyan 2002).

Based on these mentioned researches, this thesis mainly probes into the problem about how to cultivating and developing students' autonomy and independence in English reading course by the means of critical thinking. Under the construction and direction of critical thinking, English reading teaching can be effectively controlled and measured by

Sponsor: this paper is the research result of an academic research project of Kunming University: Development of Students’ Autonomous Learning based on Critical Reading and Writing

Number: XJW15004 specific standards and objectives.

\section{LITERATURE REVIEW}

\section{A. Autonomy}

Henry Holec first puts forward the concept of autonomy in Autonomy and Foreign Language learning in 1981, he defines " autonomy" as " the ability to take charge of one's learning " and as " an ability or a capacity that needs to be acquired, rather than a process”( Holec 1981).[1] According to Holec, lerner's autonomy covers the ability to fix a clear learning objective, to acquire exact learning contents and materials, to arrange learning time, place and schedule and to measure and assess learning performance and results. Other foreign scholars also give definitions to learner autonomy. (Allwright 1990; Little 1991; Dickinson 1993; Littlewood 1999).[2]

\section{B. Critical Thinking}

Critical Thinking can be traced back to its Greek etymology: "kriticos", which originally and frequently appeared in the educational practice by Socrates. John Dewey, the American philosopher and educationist, firstly brings up the concept of critical thinking, which is known as "reflective thinking”. He defines reflective thinking in his work How We Think, as: "active, persistent and careful consideration of any belief or supposed form of knowledge in the light of the grounds that support it, and the further conclusion to which it tends.” (Dewey,1910).[3] He considered the educational process as a "continual reorganization, reconstruction and transformation of experience" (Dewey, 1916). [3] According to him, truth only could be touched and acquired through reflective thinking, the "best way of thinking" as he called. Robert Ennis, believes that "critical thinking is reasonable, reflective, determining an individual's belief and behavior". David Hitchcock sums up the prominent traits of critical thinking as follows: critical thinking is meaning of thinking and reasoning; critical thinking can be applied to almost all fields; critical thinking is a checklist including the following phases: 1 . Noticing and identifying the difficulty or trouble. 2 . Defining the core problem 3. Dividing the core problem into manageable sub-problem 4. Figuring out and formulation a series of possible solutions to these sub-problems 5 . Determining what evidence or information is relevant to choosing among possible solutions to problem 6 . Formulating a plan of systematic observation or experiment which can unlock the evidence. 7. Carrying out the plan 8 . Recording the results of the observation or testing 9. Collecting the relevant testing and the opposite ideas form others 10 . Analyzing and judging the testing and opposite ideas from others 11. Drawing conclusions from the collected opposite ideas 12 . Reaching to 
a solution which is adequately supported by the evidence. ( Hitchcock, 2017)[4]

\section{COLLEGE ENGLISH READING}

\section{A. The Dilemma of English Reading Teaching}

"Why most of our schools failed to raise outstanding figures?”, this is the famous question of Qian, (Qian Xueseng) which is thought-provoking. Chinese traditional schooling, for a quite long time, has been guided by a variety of tests and examinations and led to students' surprisingly rigid thinking modes. Creative thinking and reactivation are rare among students. When faced with problems, a majority of students either definitely deny them or accept them uncritically. They fail to analyze the phenomenon or problems reasonably and judge the problems or values objectively, thus fail to make a rational and reasonable decision. They just read anything assigned to them rigidly and passively without the will to dig out more from the materials let alone enjoy and appreciate the works. If students could monitor and control consciously they thinking mode while reading, they would gain more from the reading course no matter how boring the course is. Critical thinking is the cradle for creativity. According to Dewey, critical thinking contributes greatly to individual's ability to analyze and handle problems thought to form a rational way of thinking and acting which differs essentially from the way of thinking and reacting totally triggered by instincts or desires. He holds firmly that critical thinking is the goal of education or schooling. However, there are many obstacles on the way of critical teaching and reading in reality.

- Due to the expansion of college enrolment, the student-faculty ratio is increasingly out of balance. A professional teacher has to shoulder several classes' teaching tasks without any other assistance to complete the whole of the teaching process: course designing, lecturing, homework checking and guiding, testing which covers listening, speaking, writing and reading sections. It is impossible for the teacher to probe into critical reading deeply for the reading section.

- Due to the decline of academic standards of undergraduate students, the students' elementary knowledge is poor. Besides that, students' attitudes towards English reading are not positive. Most students attend English class just out of the requirement of the authority, so they pay little attention to reading, let alone think and read critically.

- $\quad$ Teacher's limits of critical thinking cultivating. Though professional English teachers have received advanced academic training and developed critical thinking, they rarely received critical thinking mode training formally and systematically. They confine teaching to a single-mode and cannot extend it to a critical and reflective mode deliberately and consciously.

\section{B. The Current Reading Teaching approaches}

The ability of reading comprehension depends on proper reading approaches. As for the teaching practice, teachers mainly apply the three approaches in traditional English
Reading course: the top-down approach, the bottom-up approach, the interactive-compensatory approach.

\section{1) The top-down approach}

"Reading is a course of guessing with psychological language” (Goodman, 1967). [5] Readers are decoding words of the aim language with deliberate and automatic application of their individual pre-knowledge including facts, social and cultural knowledge, the topic-related knowledge, the structure of the reading article, the context information to predicting, pre-judge and meanwhile testing the previous prediction and anticipation while revising and updating at the same time. The whole reading process is a course of interaction with the writer. This approach to reading requires abundant background knowledge which matters more than vocabulary. During reading, especially for some ambiguous writing, the reader's related experience and background information are making a great difference to thorough understanding. Individual appreciation and comprehension differ greatly out of personal experience and pre-knowledge. it is no wonder that these alien culture materials are more challenging than that of native culture. Therefore, preparation of background information is paving a road to the thorough understanding. The approach emphasizes the pre-reading activities and prediction of the reading materials.

\section{2) The Bottom-up approach}

Compared with the top-down approach, the bottom-up approach believes that readers' comprehension of the material is based on the word units. Their understanding is developing to the full from their uncovering of the words one by one to the paragraphs one after another and then to the whole article. According to this mode, reading is no more than a word decoding process, whose core challenge lies in words. For this approach, a considerable vocabulary is helpful for just "Reading the lines". Accordingly, vocabulary teaching plays a vital role, which mainly includes words explanation and related usage illustration.

\section{3) The Interactive-compensatory approach}

The Interactive-compensatory approach was put forward by Stanovich in 1980, which is a combination of the top-down approach and the bottom-up approach and accepted by most educators. This mode simultaneously stresses the importance and significance of both vocabulary and background knowledge, which suggests the core nature of the reading task.

Reading is normally considered practiced on three levels: reading the line, reading between the lines; reading beyond the lines. The literal reading is the basic level; Reading and reasoning aim to reckon and guess the implication and ideas not expressed in the ground of details, facts. The highest level of reading called image reading. (Reading beyond the lines), which requires individual reasoning ability, imagination and creative ability.

\section{COMBINING CRITICAL THINKING WITH ENGLISH READING COURSE}

Reading course for language learning is originally designed for words learning and writing skills gaining. But currently, it reaches into more subjects and fields. Reading program is carried out in various institutions, education units, educational 
programs and bears various goals not only aiming to promote language ability but also to provoke reasonable and rational thinking.

The famous British educator professor Barnett $\mathrm{R}$ believes that "a learning society in its fullest sense where students are encouraged to critique both ways of knowing and of acting in the world rather than focusing narrowly on skills and what works.... to live the critical life in higher education, and engender a critical spirit” ( Barnett, 1997). [5] According to Barnett, the nature of high education is to enable students to understand and absorb what they learned, what they do and can transfer the experience into inner knowing used for various circumstances. So cultivating of critical thinking is one of the major goals of high education, for such thinking mode is the ability to shape, reshape and refresh individual minds. According to Hitchcock, critical thinking training and developing needs systematic phases and strategies. Therefore, such kind of training needs the exact form. This thesis uses English reading serves as the carrier for critical thinking. This course compromises the strategies, techniques, habits and attitudes of critical thinking.

English reading course requires students to think over the assigned task carefully, actively and deeply and reconstruct their knowledge to measure and test their understandings. The task is centered on specific issues, problems, doubts, which practiced with "critical edge".

Problem-solving courser is highly related with critical thinking which a tool is and device for learning in problem-solving thus this kind of teaching mode (PBL) is considered as the main device for critical thinking cultivating.

\section{A. The phases of PBL with critical thinking}

Reading program can be fused with different subjects including accounting, business, engineering, history and so on. No matter what the content is, the following phases are recommended as the usual $\mathrm{PBL}$ approach to promoting students' critical sense. The following phrases also contain exact reading strategies.

\section{1) Head Start}

Firstly, the teacher puts forward the issue or topic in advance and gives the students related materials. Most of all, this step is designed to preview called head start. Previewing aims to let students know and get familiar with the related information. In practice, brainstorming is often adopted to think about what do we already know about the topic? This part also stimulates their background knowledge so that they can predict their reading content. It refers to the question: what do we think we will learn about the topic when we read the passage?

\section{2) During Reading}

Secondly, during reading, students begin click and clunk to train students to monitor and watch their own reading. They should pay attention to their accuracy and efficiency. Were there any parts that were hared to understand (clunk)? How can we fix the clunks? Use Fix-up strategies:

Reread the sentence and look for key ideas to help they understand the word;
Reread the sentence with the clunk and the sentences before or after the clunk;

looking for clues;

Break the word apart and look for smaller words.

Look for a prefix or suffix in the word.

Meanwhile, they are supposed to get the gist, figuring out the main characters, places, the events and related viewpoints. What is the most important person, place, or thing? What is the most important idea about the person, place or thing? Ask the students to read and study the materials and then retell the main plot, describe the major characters and the key ideas.

In reciprocal reading, students are in charge of the reading process. During reading, they are required to practice summarizing, questioning, clarifying and predicting. Students are encouraged to question in the place of the teacher. Questioning is the most important quality of reading ability. One is poor at the questioning is also poor at critical thinking. It is a question that pushes and promotes the thinking actively not the answer. Because questioning helps one identifies his task and problem while answer means ceasing thinking. Only when the answer stimulates new questions, thinking keeps acting. Only those smart and active questions can stimulate and promote critical thinking. However, most questions from the students are rigid and superficial failing to trigger active thinking. Such kind of questions implies the sluggishness of their thinking mode. So how can we train our students to question effectively and deeply? Let me first introduce the effective classification of questions. Questions sorting serve as a quick-starter for effective questioning.

1. Questions about details and facts whose answer is definite and unique. For example: What's your name?; what's the size of the room?

2. Questions about preference whose answer differs personally. Such kind of questions leads to absolutely subjective answers. For example: Travelling in the cities or on the beach, which does you prefer? Would you like to go shopping?

3. Questions about judgments. This kind of questions is open to various answers requiring discussion and judgments. Those questions are dialectical and the answers differ greatly in terms of quality and effect in the demonstration. The answer is comparatively superior to each other in the proper scope of possible answers. For example: How can you clarify the major problems in our country's economics?; should the death penalty be abolished? As for this kind of questions about judgments, one needs the universal standards to assess and evaluate the answers. The standards on thinking refer to: clarity, depth, relevance, logics, accuracy, breadth, and objectivity. Socratic questioning mode serves an effectively systematic questioning. A critical thinker must be willing to think and able to think. Only when questioning, one is thinking. Socratic questioning can guide one thinks effectively.

Phrases of Socratic Questioning:

1. Try one's best to understand the basis of those being 
discussed or believed and use questions to go further in their meanings.

2. Try to find out those ideas that cannot be proven to be true but interdepend with other points. Find out the relation among them and ponder deeply on them.

3. Demand updating needs from the ideas.

4. Bear in mind that all questions are based on those forgoing ones. While questioning, hold an open attitude toward and go further with the previous questions.

Strategies of Socratic Questioning:

1. Focus on the type or mold of the questions;

2. Focus on the universal assessing standards of thinking;

3. Focus on the analyzing of parts of arguments;

4. Focus on dividing the core problem into sub-problems and decide the priority level of those sub-problems;

5. Focus on the principal contradiction of difficulty.

Summary: It is a question that determines thinking. Questions are a reflection of thinking, meaning a great deal to a critical thinker. Those, who think critically, are always able to classify questions clearly. For critical thinkers, they are able to raise questions that useful and helpful in realizing the goals together with those questions that are effective in assessing our goals. The socratic tradition of an inquiry gives an effective device to optimize the questioning.

\section{3) After Reading}

Thirdly, students are asked to wrap up their tasks. The teacher asks students to answer related questions and write down their comments and reflection based on their understanding. Usually, learning logs are often adopted. Finally, the teacher gives feedback about students' homework and illustrates further critical ideas concerning the task.

\section{B. The principles of Critical teaching in reading course.}

Based on "critical thinking by design" supports by Joanne Kurfiss, teachers can find a wide variety of goal-directed activities for thinking and training.

1. Identifying analogies and the relevant relationships between facts, information and opinions.

2. Determining the relevance and validity of those facts, details and information that are useful to problem-solving.

3. Working out the possible solutions or alternative means of problem-solving and evaluate them.

4. Encourage and promote interaction among learners as they read: learn in a group usually enhance individual achievement.

5. Putting forward open-ended questions that do not assume the uniquely right answer which stimulates students to think and respond creatively.

6. Teaching to transfer. Critical thinking skills should work well. They can be applied to other circumstances, other situation, cross areas and levels not only be confined to a narrow scope, say in the classroom study.

Summary: Critical thinking is a kind of capacity that can be trained and developed with deliberately designed grogram. Educators should have faith in reasoning and critical thinking and hold them for educational goals then fuse into the specific teaching practice. To gain any kind of skill needs labor, effort and will. Encouragement and inspiration from teachers are significantly important for students who are exercising their thinking like exercising their muscle. The more they exercise, the stronger they will be.

\section{Student Autonomy}

\section{A. The principles of autonomy}

The concept of "Autonomy” was originally introduced into foreign language teaching by Henri Holec in 1981. Holec holds that from the learner's perspective, autonomy means the ability to clarify the specific study goals, to define the scope of study contents, to fix study place and schedule and to assess the overall learning process. Such requirements are in accordance with that of critical thinking ability. Thus, critical thinking cultivation is a device for developing and promoting student autonomy.

Given Chinese students English learning features, our student autonomy shall cover the following aspects: knowing and understanding the teaching objects and requirements; identifying their learning goal and fixing the suitable learning scheme; applying effective learning strategies; monitoring and watching the validly of learning strategies; assessing the learning efficiency.

\section{B. The analysis of current student autonomy}

(1) About the teaching objectives: most students can manage to follow the teacher' syllabus, but they often fail to identify the teaching goal for every period of class. So teachers need to reform their teaching form to emphasis the teaching goals. Only by doing so, can students experience the hosting feeling during learning.

(2) About the learning schedule: Most students rarely make up their individual schemes and schedules only when the teacher requires, let alone adjust their learning plan. They just follow and listen to what the teacher requires and rigidly finish related assigned tasks. It seems that it is the teacher who is in charge of everything concerning the English course. Students are too passive to be their own hosts in their learning.

(3) About the learning strategies: Most students know little about learning strategies. They just learn with habits unconsciously as they do for ages. Traditional English class attaches more importance to knowledge than to learning strategies. Learn to learn is the core of education on different levels.

(4) About the strategies monitoring: Students cannot watch and monitor the effect and efficiency of the application of learning strategies. Though they may notice some strategies working wrong, they have no idea about how to adjust that.

(5) About learning cooperation: learning cooperation consists of student autonomy. Autonomy is definitely not learning by oneself, it needs cooperation to deepen and promote an individual's understanding of oneself and of problem.

Summary: The non-English major students' autonomy is not fully developed. Sense of self-management should be fused into class teaching. Examination-oriented education 
mode restrains student active and positive learning motive and limits them to wider alternatives to learning strategies. Lifelong education and lifelong learning must be rooted in every leaning mind. An excellent learner is always an experienced thinker; he can control the overall learning process, set a scientific plan and carry it out persistently with a spirit of discovery.

\section{CONCLUSION}

Critical thinking is the art of taking charge of your own mind. The value is obviously simple: if we can take charge of our own mind, we can take charge of our lives and our studies in every fields and area. As John Henry Newman argues the aim of a university education in The Ideas of University, " But a university raining is the great but ordinary means to a great but ordinary end; it aims at raising the intellectual tone of society, at cultivating the public mind, at purifying the national taste, as supplying true principles it teaches him to see things as they are, to go right to the point, to disentangle a skein of thought, to detect what is sophistical, and to discard what is irrelevant. It prepares him to fill any post with credit and to master any subject with facility.” Only through professional high education, one can grow into the ideal individual. Through reading, with a critical mind, one can open the wider vision of his view of the world and of life. This ability would hatch his real autonomy in thinking and learning.

\section{REFERENCES}

[1] Holec, H. Autonomy and Foreign Language Learning [M]. Oxford: Pergamon, 1981

[2] Little, D. Leaner Autonomy: Definition, Issues and Problems. [M]. Dublin: Authentik,1991

[3] John, Dewey How we Think [M]. The People's Education Press,2005

[4] Ennis, R. Goals for critical Thinking. Champaign, University of Illinois. 1985

[5] John Henry Newman, The Ideas of A University.[M] University of Notre Dame Press, 1990

[6] Pang Guowei, Autonomy Learning: Strategies for teaching and learning. The Southern China Normal University Press,2003

[7] Long, M. Input and Second Language Acquisition Theory[A]New York: Newbury House, 1989

[8] Simon and Schuster, The Art of Thinking. New York: Fraser. 2004 